\title{
Trash to treasure: Production of biofuels and commodity chemicals via syngas
} fermenting microorganisms

\author{
Latif, Haythem; Zeidan, Ahmad; Nielsen, Alex Toftgaard; Zengler, Karsten
}

Published in:

Current Opinion in Biotechnology

Link to article, DOI:

10.1016/j.copbio.2013.12.001

Publication date:

2014

Document Version

Publisher's PDF, also known as Version of record

Link back to DTU Orbit

Citation (APA):

Latif, H., Zeidan, A., Nielsen, A. T., \& Zengler, K. (2014). Trash to treasure: Production of biofuels and commodity chemicals via syngas fermenting microorganisms. Current Opinion in Biotechnology, 27, 79-87. https://doi.org/10.1016/j.copbio.2013.12.001

\section{General rights}

Copyright and moral rights for the publications made accessible in the public portal are retained by the authors and/or other copyright owners and it is a condition of accessing publications that users recognise and abide by the legal requirements associated with these rights.

- Users may download and print one copy of any publication from the public portal for the purpose of private study or research.

- You may not further distribute the material or use it for any profit-making activity or commercial gain

- You may freely distribute the URL identifying the publication in the public portal 


\section{Trash to treasure: production of biofuels and commodity chemicals via syngas fermenting microorganisms Haythem Latif ${ }^{1}$, Ahmad A Zeidan ${ }^{2}$, Alex T Nielsen ${ }^{2}$ and Karsten Zengler ${ }^{1,2}$}

Fermentation of syngas is a means through which unutilized organic waste streams can be converted biologically into biofuels and commodity chemicals. Despite recent advances, several issues remain which limit implementation of industrialscale syngas fermentation processes. At the cellular level, the energy conservation mechanism of syngas fermenting microorganisms has not yet been entirely elucidated. Furthermore, there was a lack of genetic tools to study and ultimately enhance their metabolic capabilities. Recently, substantial progress has been made in understanding the intricate energy conservation mechanisms of these microorganisms. Given the complex relationship between energy conservation and metabolism, strain design greatly benefits from systems-level approaches. Numerous genetic manipulation tools have also been developed, paving the way for the use of metabolic engineering and systems biology approaches. Rational strain designs can now be deployed resulting in desirable phenotypic traits for large-scale production.

\footnotetext{
Addresses

${ }^{1}$ University of California San Diego, Department of Bioengineering, La Jolla, CA 92039, United States

${ }^{2}$ The Novo Nordisk Foundation Center for Biosustainability, Technical University of Denmark, Kogle Allé 6, Hørsholm 2970, Denmark
}

Corresponding author: Zengler, Karsten (kzengler@ucsd.edu, kzengler@eng.ucsd.edu)

Current Opinion in Biotechnology 2014, 27:79-87

This review comes from a themed issue on Energy biotechnology Edited by Arthur J Ragauskas and Korneel Rabaey

0958-1669/\$ - see front matter, (C) 2013 Elsevier Ltd. All rights reserved.

http://dx.doi.org/10.1016/j.copbio.2013.12.001

\section{Introduction}

Heightened concerns over global warming and fossil fuel supply and prices have led to a paradigm shift in perceived routes to chemical commodity production and energy generation. The majority of the world community has set challenging targets for reductions in greenhouse gas emissions to be achieved in part through the development of sustainable routes to chemicals, fuels, and energy production. The EU has targeted a $10 \%$ share of renewable biofuels in the transportation sector by 2020 [1] while the US has mandated the production of 36 billion gallons of biofuels by 2022 [2]. The biological conversion of renewable lignocellulosic biomass such as wheat straw, spruce, switchgrass, and poplar to biofuels is expected to play a prominent role in achieving these goals. These forms of biomass address many of the concerns associated with the production of first-generation biofuels [3,4]. However, 10-35\% of lignocellulosic biomass is composed of lignin [5-7], which is highly resistant to breakdown by the vast majority of microorganisms [8]. Thus, if the EU and US cellulosic biofuel targets are realized, land allocation for biofuel production will increase and megatons of organic waste will be generated.

This organic waste provides a significant resource of biomass that can be utilized for producing biofuels as well as commodity chemicals. Through gasification, virtually any form of organic matter can be converted into a mixture of carbon monoxide $(\mathrm{CO})$, carbon dioxide $\left(\mathrm{CO}_{2}\right)$, and hydrogen $\left(\mathrm{H}_{2}\right)$, referred to as synthesis gas or syngas. Gasification involves high temperature (usually 600$900^{\circ} \mathrm{C}$ ) partial oxidation of biomass in the presence of a gasifying agent (e.g. oxygen or steam) resulting in the production of gas with significant amounts of $\mathrm{CO}$ and $\mathrm{H}_{2}$ [9]. Syngas can be metabolized by certain carbon-fixing microorganisms and converted to valuable multi-carbon compounds such as acetate, ethanol, butanol, butyrate, and 2,3-butanediol [10,11]. This process, known as syngas fermentation, provides an attractive means for converting low cost organic substrates and waste streams into valuable chemicals. Syngas fermentation has numerous advantages when compared to thermo-chemical processes such as Fischer-Tropsch synthesis. These include a higher tolerance for impurities such as sulfur compounds, a wider range of usable $\mathrm{H}_{2}, \mathrm{CO}_{2}$, and $\mathrm{CO}$ mixtures, a lower operating-temperature and -pressure, and higher product yield and uniformity. However, wide use of these syngas fermenting microorganisms as production hosts is currently hindered by several factors, including low volumetric product titers, product feedback inhibition, and low gas-liquid mass transfer coefficient (kLa) [12]. Though some of these challenges can be overcome, in part, through process improvements, a fundamental understanding of the biology enabling syngas fermentation is needed to guide those design strategies and to provide targets for cellular engineering. Thus, the biggest challenge facing process development for syngas fermentation may be the lack of tools and technologies that will further our understanding of the fundamental biology behind these versatile microorganisms. This review focuses on these unique microorganisms, their 
metabolic and energy conservation pathways, and the genetic engineering strategies that together will guide advances in the use of syngas fermentation for the production of biofuels and commodity chemicals.

\section{Syngas fermenting microorganisms}

A diverse range of microorganisms that can metabolize syngas and produce multi-carbon compounds have been identified (Figure 1). These organisms are ubiquitous in numerous habitats such as soils, marine sediments, and feces, exhibit various morphologies (e.g. rods, cocci, or spirochetes), have a wide range of optimal growth temperatures (psychrophilic, mesophilic, or thermophilic), and demonstrate different tolerance toward molecular oxygen [13]. Syngas fermenting microorganisms also have diverse metabolic capabilities, resulting in the formation of a variety of native products such as acetate, ethanol, butanol, butyrate, formate, $\mathrm{H}_{2}, \mathrm{H}_{2} \mathrm{~S}$, and traces of methane $[10,11,13-15]$. Though some methanogens are known to synthesize multi-carbon organics from syngas, the vast majority of syngas fermenting organisms are acetogens (Figure 1). Acetogens are anaerobes that assimilate $\mathrm{CO}_{2}$ via the Wood-Ljungdahl (WL) pathway, also referred to as the reductive acetyl-CoA pathway. Though we focus here mainly on autotrophic conversion of syngas in acetogens, the WL pathway is also active during heterotrophic growth.

\section{The Wood-Ljungdahl pathway}

The WL pathway is hypothesized to be the most ancient $\mathrm{CO}_{2}$ fixation pathway [16]. However, the apparent simplicity of this linear pathway belies the complex, interconnected energy conservation mechanisms that enable growth on syngas $\left[13,17^{\bullet \bullet}\right]$. Only a short overview of the pathway will be given here since the WL pathway has been extensively reviewed elsewhere [13,18-20]. Figure 2 shows the complete WL pathway with electron

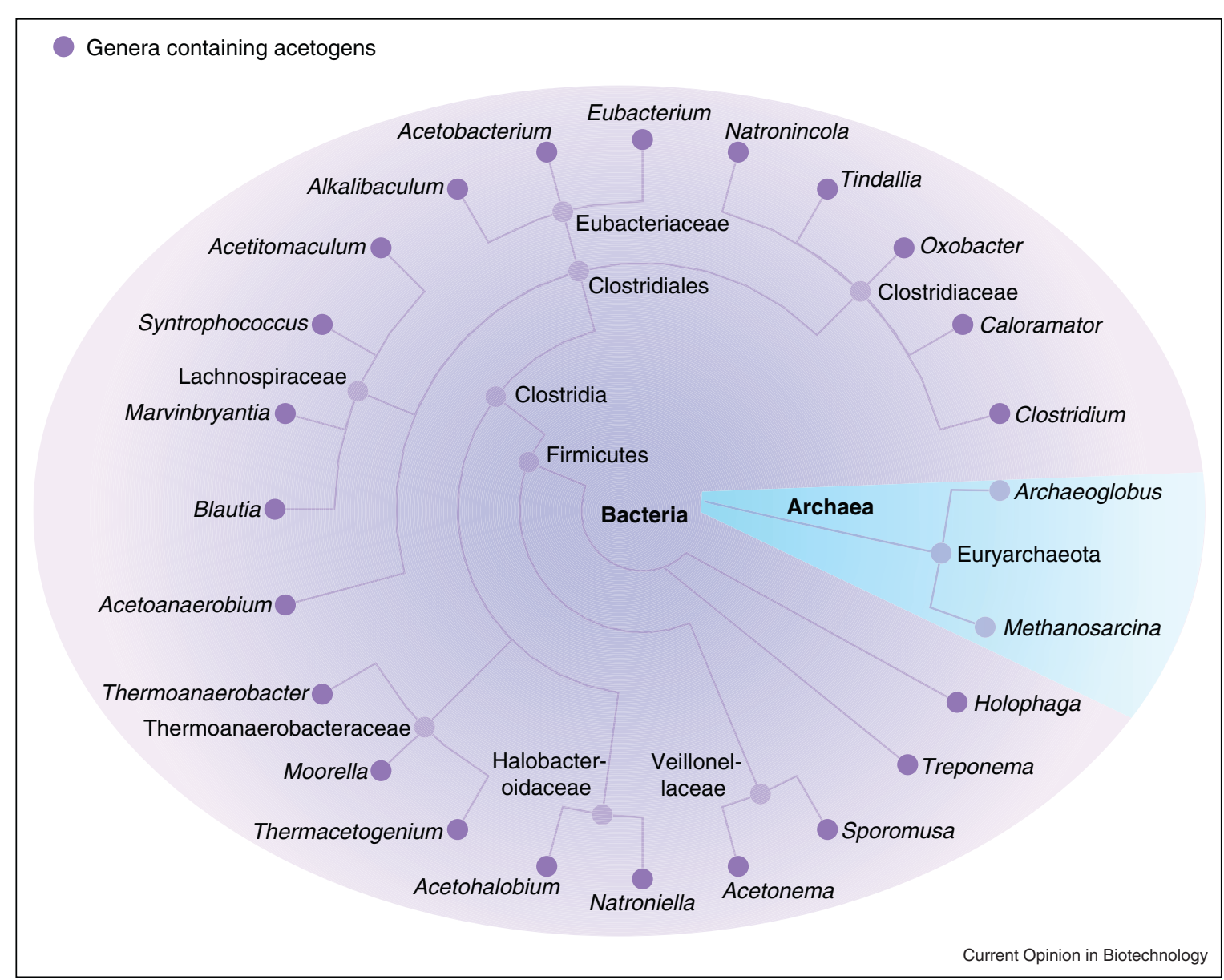

Syngas fermenting organisms known to produce multi-carbon organic compounds. Shown is the taxonomic classification of the genera capable of converting syngas to multi-carbon compounds based on organisms found in [10,11,13-15]. With the exception of two archaeal genera, all of the genera that produce multi-carbon organic compounds are considered acetogens. Genera are classified based on NCBI's current taxonomic nomenclature and categorization. 


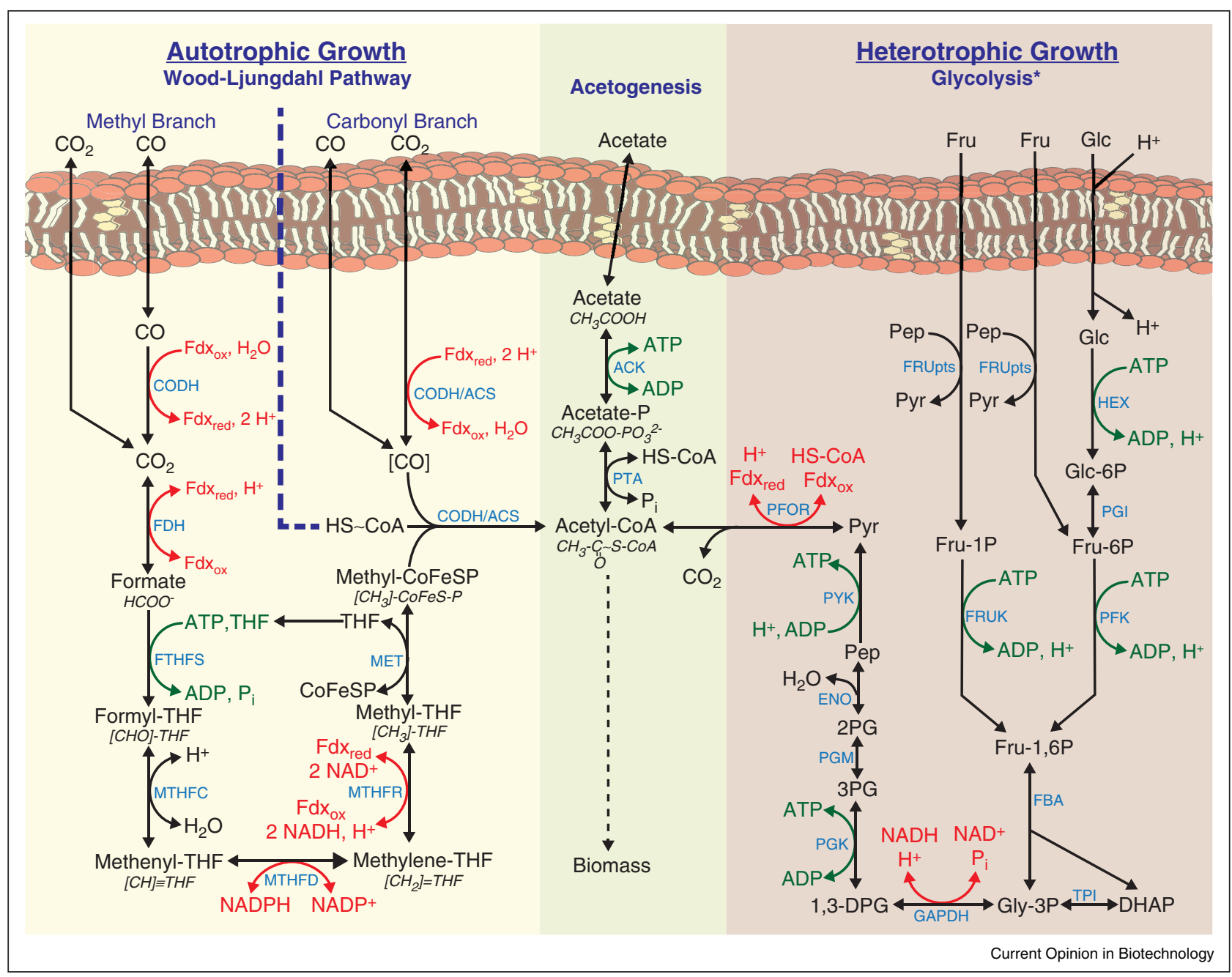

The Wood-Ljungdahl pathway and its connection to heterotrophic metabolism. Shown is the WL pathway for Clostridium ljungdahlii as assessed in [21,22] with reduced ferredoxin, $\mathrm{NADH}$, and $\mathrm{NADPH}$ serving as electron carriers during $\mathrm{CO}_{2}$ fixation. The left panel shows the Methyl and Carbonyl branches of the WL pathway leading to either acetate formation or assimilation of acetyl-CoA into biomass. The right panel depicts fermentation through glycolysis for fructose and glucose. The electrons generated during glycolysis are used to produce an additional acetyl-CoA through the WL pathway. Redox reactions involving cofactor intermediates are shown in red with each cofactor reaction involving the transfer of two electrons. ATP consumption/generation reactions are shown in green. Reactants abbreviations: Acetate-P, acetate phosphate; CoA, coenzyme A; CoFeSP, corrinoid iron sulfur protein; THF, tetrahydrafolate; $\mathrm{Fdx}_{\mathrm{ox}}$, oxidized ferredoxin; Fdx $\mathrm{red}_{\text {ed }}$, reduced ferredoxin; Pyr, pyruvate; Pep, phosphoenolpyruvate; 2PG, 2phosphoglycerate; 3PG, 3-phosphoglycerate; 1,3-DPG, 1,3-bisphosphoglycerate; DHAP, dihydroxyacetone phosphate; Gly-3P, glycerol 3phosphate; Fru-1,6P, fructose 1,6-bisphosphate; Fru-6P, fructose 6-phosphate; Glc-6P, glucose 6-phosphate; Glc, glucose; Fru-1P, fructose 1phosphate; Pyr, pyruvate; Pep, phosphoenolpyruvate; Fru, fructose. Enzyme abbreviations (in blue): ACK, acetate kinase; PTA, phosphotransacetylase; MET, methyl transferase; MTHFR, methylene tetrahydrofolate reductase; MTHFD, methylene tetrahydrofolate dehydrogenase; MTHFC, methenyl tetrahydrofolate cyclohydrolase; FTHFS, formyl tetrahydrofolate synthase; FDH, formate dehydrogenase; CODH/ ACS, carbon monoxide dehydrogenase/acetyl-CoA synthase; PFOR, Pyruvate ferredoxin oxidoreductase; PGK, phosphoglycerate kinase; ENO, enolase; PGM, phosphoglycerate mutase; PGK, phosphoglycerate kinase; PFK, phosphofructokinase; TPI, triose phosphate isomerase; FBA, fructose-biphosphate aldolase; FRUK, fructokinase; PFK, phosphofructokinase; PGI, phosphoglucose isomerase; HEX, hexokinase; FRUT, fructose transporter. ${ }^{*}$ The stoichiometry shown represents conversion of a single Gly-3P molecule, thus only half of the payoff phase of glycolysis is shown.

carrier proteins and cofactors as proposed for Clostridium ljungdahlii $[21,22]$.

The WL pathway consists of two branches: the methyl branch and the carbonyl branch. These two branches provide reduced, single-carbon molecules that contribute to the formation of acetyl-CoA, which can then be assimilated into cellular biomass or converted to acetate. For simplicity, the case of autotrophic growth on $\mathrm{CO}_{2}$ and $\mathrm{H}_{2}$ will be examined first. On the methyl branch, a sixelectron reduction of $\mathrm{CO}_{2}$ yields a methyl moiety while the carbonyl branch reduces $\mathrm{CO}_{2}$ to $\mathrm{CO}$ which is bound to 
the carbon monoxide dehydrogenase/acetyl-CoA synthase complex (CODH/ACS). CODH/ACS unites the two branches by reacting these products with coenzyme A to yield acetyl-CoA. Thus, a total of one ATP (needed for formate fixation) and eight electrons are needed to fix two molecules of $\mathrm{CO}_{2}$. With $\mathrm{H}_{2}$ as the sole electron donor, hydrogenases reduce cofactor intermediates (e.g. reduced ferredoxin, $\mathrm{NAD}(\mathrm{P}) \mathrm{H}$ ) that are subsequently used to reduce $\mathrm{CO}_{2}$. $\mathrm{CO}$, typically the most abundant carbon species in syngas [23], is often able to sustain autotrophic growth through the WL pathway as the sole electron donor. In this case, $\mathrm{CODH}$ carries out a water-gas shift reaction where water and $\mathrm{CO}$ yield $\mathrm{CO}_{2}$, two protons, and two electrons providing the necessary inputs for the formate dehydrogenase reaction on the methyl branch. CO is bound directly by CODH/ACS on the carbonyl branch requiring no reduction. Thus, the conversion of two CO to acetyl-CoA requires one ATP and four electrons. The formation of acetate from acetylCoA yields one molecule of ATP through substrate level phosphorylation (SLP). As a whole, the WL pathway generates no net ATP through SLP and the transfer of four or eight electrons from reduced ferredoxin, NADH, or NADPH to fix syngas.

During syngas fermentation electrons are donated by $\mathrm{H}_{2}$ or CO. However, the WL pathway is capable of sourcing electrons from many compounds under heterotrophic conditions including alcohols, organic acids, and simple sugars [13]. This enables acetogens to have near complete stoichiometric conversion of hexoses to acetate. From glycolysis, acetogens typically synthesize two acetates, four ATPs (via SLP), and two $\mathrm{CO}_{2}$ 's from one mole of hexose. The $\mathrm{CO}_{2}$ generated can be fixed by the WL pathway using the eight electrons generated during glycolysis. Thus, a third mole of acetate is produced but no net ATP is synthesized via SLP. The overall conversion of hexose yields three moles of acetate and four moles of ATP via SLP.

\section{Energy conservation in acetogens}

Since the WL pathway yields no net ATP through SLP, a chemiosmotic gradient is necessary to drive ATP synthesis under autotrophic conditions, such as syngas fermentation. Some acetogens utilize anaerobic respiration (also known as electron transport phosphorylation, ETP), for energy conservation such as Moorella thermoacetica [2426]. However, many acetogens do not possess electron transport chain proteins. Recently, flavin-based electron bifurcation (FBEB) has been described as an alternative means for energy conservation in certain bacteria $\left[17^{\bullet \bullet}\right]$. FBEB couples exergonic redox reactions with endergonic redox reactions. Certain FBEB complexes couple this redox reaction with the translocation of cations thereby forming a chemiosmotic gradient. An example of this is the Rnf complex, which is found in many microorganisms. The Rnf complex is a membrane associated FBEB system that pumps $\mathrm{Na}^{+}$or $\mathrm{H}^{+}$ions out of the cell. This is driven by coupling the oxidation of reduced ferredoxin with the reduction of $\mathrm{NAD}^{+}$[27] (Figure 3). In the acetogen Acetobacterium woodii, a $\mathrm{Na}^{+}$gradient generated by the Rnf complex is converted to ATP by a $\mathrm{Na}^{+} \mathrm{F}_{1} \mathrm{~F}_{0}$ ATP synthase [28-31]. A proton translocating Rnf complex in $C$. ljungdahlii has recently been shown to be essential for autotrophic growth $\left[32^{\circ}\right]$. Studies have also revealed soluble FBEB complexes in acetogens. A $[\mathrm{FeFe}]$-hydrogenase (Figure 3) that reduces ferredoxin and $\mathrm{NAD}^{+}$through the oxidation of $\mathrm{H}_{2}$ has been identified in A. woodii [33] and $M$. thermoacetica $\left[34^{\bullet}, 35\right]$. Recently, an NADP-specific [FeFe]-hydrogenase has been discovered in Clostridium autoethanogenum [36]. An Nfn complex similar to that of Clostridium kluyveri [37] (Figure 3) was identified in $M$. thermoacetica as well [34 $\left.4^{\circ}\right]$. This complex reduces $\mathrm{NADP}^{+}$while oxidizing NADH and ferredoxin. Furthermore, it has been suggested that the WL reaction catalyzed by methylene tetrahydrofolate reductase (MTHFR) is also an electron bifurcation reaction in A. woodii [31] and C. ljungdahlii [21,22] (Figure 2).

Together, membrane bound and cytoplasmic FBEB reactions create an intricate network of redox reactions that collectively contribute to energy conservation and redox homeostasis. For example, it is thought that energy conservation during hydrogen-dependent caffeate respiration in $A$. woodii is governed by three FBEB complexes working in concert; the membrane associated Rnf, the soluble [FeFe]-hydrogenase, and the soluble caffeyl-CoA reductase-Etf complex responsible for oxidation of NADH and reduction of ferredoxin [38]. FBEB reactions metabolically 'hard-wire' the redox state of the different cofactor pools and electron carrier proteins. Thus, these reactions can be envisioned as moving together in response to changes in metabolism and energy conservation.

\section{Advances in genetic manipulation tools}

A lack of versatile genetic tools for manipulating syngas fermenters has hindered the ability to engineer this group of microorganisms. However, there has been remarkable progress in the development of genetic systems for numerous industrially important anaerobes, especially clostridia, in recent years. Protocols for gene deletion via double crossover homologous recombination were recently developed for the syngas fermenting $C$. ljungdahlii [39 ${ }^{\circ}$ ] and $M$. thermoacetica [40-42]. Uracil-auxotrophic mutants of $M$. thermoacetica $\left[41^{\circ}\right]$ and $C$. thermocellum [43] were constructed allowing for both positive- and counter-selection of desired recombinants. Moreover, methods employing bacterial group II intron for gene deletion $\left[44,45,46^{\circ}\right]$ and a Bacillus subtilis resolvase [47-49] were developed as universal genetic tools for Clostridium species. Genetic systems were also established based on replicative plasmids capable of double crossover chromosomal integration [50], inducible 


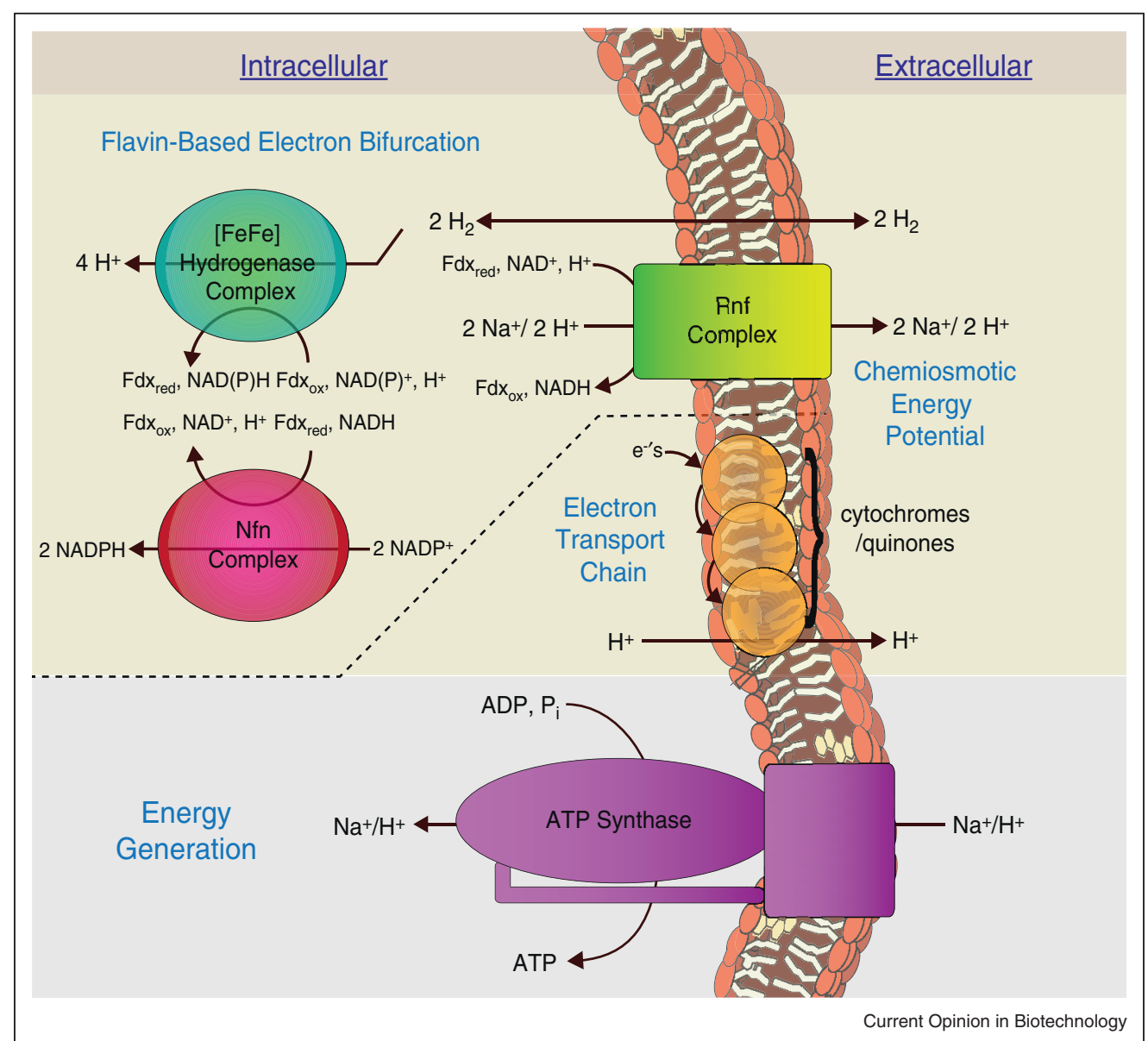

Energy conservation during syngas fermentation. Shown are examples of protein complexes found in acetogens that conserve energy during syngas fermentation. Syngas fermentation produces no net ATP through substrate level phosphorylation. Thus, a chemiosmotic gradient is utilized to drive ATP synthesis. This gradient is achieved predominantly through ion translocation via electron transport chain proteins or through membrane-bound flavin-based electron bifurcation (FBEB) complexes such as the Rnf. Soluble FBEB complexes like the [FeFe]-hydrogenase and Nfn complex have also been identified in acetogens. These, as well as other complexes (not shown) are important for maintaining cellular redox balance. Energy generation occurs through the ATP synthase. Acetogens such as Clostridium ljungdahlii and Moorella thermoacetica utilize a $\mathrm{H}^{+}$gradient while others like Acetobacterium woodii use $\mathrm{Na}^{+}$.

counter-selection for markerless gene deletions/insertions at any desired genomic loci [51], coupled expression of heterologous selectable markers to a chromosomal promoter to select for double crossover events [52 $]$, and antisense RNA for protein down-regulation [53]. Reverse genetic tools in the form of transposon mutant libraries were generated using a mariner-based system in the autotrophic pathogen $C$. difficile and in $C$. perfringens [54,55] and a Tn1545-based system in C. cellulolyticum [56].

\section{Strain engineering to obtain desired production phenotypes}

With the availability of such genetic tools and the recent advances in whole-genome sequencing, combined metabolic engineering and synthetic biology approaches can be applied to accelerate the development of syngas fermentation processes. Boosting the yield and productivity of syngas fermenters and broadening the spectrum of chemicals and fuels that can be produced are immediate goals. As a proof of concept, the deletion of the bifunctional aldehyde/alcohol dehydrogenase in $C$. ljungdahlii resulted in increased acetate yield on the expense of ethanol $\left[39^{\circ}\right]$. The functionality of a construct harboring the known acetone pathway of $C$. acetobutylicum was demonstrated in $C$. aceticum, enabling the latter to produce $8 \mathrm{mg} / \mathrm{L}$ of acetone from a mixture of $\mathrm{H}_{2}$ and $\mathrm{CO}_{2}$ [11,57]. Similarly, plasmids bearing heterologous genes for the butanol synthesis pathway of $C$. acetobutylicum were introduced into $C$. ljungdahlii allowing for low levels of butanol production [21]. Butanol was subsequently 
converted to butyrate at the end of the fermentation, indicating the need for further genetic modifications to prevent the loss of butanol. Yet, the reversibility of this and similar alcohol forming enzymatic reactions was exploited by providing external short-chain carboxylic acids and syngas to $C$. ljungdahlii for the production of alcohols [58].

In addition to improved yield and product-range of acetogens, engineering strategies targeting other limitations identified at industrial-scale may be considered. Among these limitations are low syngas kLa, low cell-biomass, sporulation, as well as substrate and product inhibition. Engineering syngas fermenting microorganisms for enhanced biofilm development can help overcome their inherently low biomass yield while enabling the use of reactors with enhanced gas mass transfer rates such as airlift reactors [59] or membrane biofilm reactors [60] as well as other types of biofilm-based reactors suitable for syngas fermentation [15,57]. More effective biofilms can be formed by increased exopolysaccharide production [61] or by manipulating other factors that are known to modulate biofilm formation in Clostridium species [62]. Longer fermentation increases the possibility of spore formation. Inactivating Spo0A, the master regulator of sporulation in Clostridium species [ $63^{\circ}$ ], was thought to be the obvious strategy for abolishing sporulation [64]. However, Spo0A's involvement in solvent production $[65,66]$ and biofilm formation $\left[62,63^{\circ}, 67\right]$ will necessitate tuned expression rather than complete inactivation. Alternatively, sporulation regulators downstream to Spo0A can be targeted for creating asporogenous strains, as was demonstrated for C. acetobutylicum [64] and C. phytofermentans [68].

Phenotypes with improved fitness for syngas fermentation can also be obtained by adaptive laboratory evolution (ALE) [69-71]. Various ALE approaches can be employed to obtain highly desirable industrial traits such as optimal growth during syngas fermentation and tolerance to high concentrations of substrates (e.g. CO) or products (e.g. ethanol). For instance, ALE approaches were used to generate strains of Butyribacterium methylotrophicum that were adapted to growth in a pure COheadspace [72]. Ethanol tolerant strains of Escherichia coli and subsequent genome-scale analysis provided insights into the metabolic and regulatory mechanisms that caused that phenotype to emerge [73,74]. A similar approach can be applied to syngas fermenting production strains.

\section{Rational strain design and process optimization through a systems-level approach}

Currently, little is known about the possibility of completely redirecting the metabolic fluxes from acetate to other products during syngas fermentation or its effect on cellular energetics. Recently, Tyrurin and coworkers reported in a series of publications on completely abolishing acetate production in an undisclosed Clostridium strain, in favor of acetone [75], ethanol [76,77], butanol [78], mevalonate [78], methanol, or formate [79] production during autotrophic growth on syngas. However, eliminating acetate synthesis by deletion of the phosphotransacetylase and/or acetate kinase (ack) genes presumably prevents the concurrent synthesis of ATP (via SLP) by Ack. The impact this change has on the growth energetics in these strains is not yet fully understood.

Perhaps the most effective way for rational strain design is through the use of genome-scale metabolic models. Genome-scale models have successfully been implemented in rational strain design $[80,81]$. Recently, the first comprehensive reconstruction of metabolism in an acetogen has been generated [22]. Using this C. ljungdahlii model, simulation of a $\Delta a c k$ mutant predicted conditional essentiality. In silico growth was observed under heterotrophic conditions and under autotrophic growth with $\mathrm{CO}$ as the electron donor. However, growth on $\mathrm{H}_{2}$ as the sole electron donor was essential depending on the cofactor specificity of the [FeFe]-hydrogenase [22]. This conditional essentiality is attributed to differences in the redox state of the different electron carrier pools and their ability to contribute to FBEB-based energy conservation to compensate for the lost ATP generated during acetate synthesis. Thus, it is extremely important to detail the exact mechanisms of energy conservation, including the stoichiometry of the ATPase reaction, in the metabolic network reconstruction for more realistic phenotype predictions. Another model of the WL pathway in C. ljungdahlii was used to determine the ATP yield per mol CO consumed and the proton translocation per electron transfer of the Rnf complex [58]. Lastly, metabolic modeling has been used to optimize media formulations, for instance, based on energy demands [82]. These models can help optimize and reduce the cost of media, which is a challenge the needs to be addressed before commercial deployment of syngas fermentation $[83,84]$.

\section{Summary and opportunities}

Fermentation of syngas into biochemicals using acetogenic microorganisms offers an important economic potential for biofuel and commodity chemical production. Gasification allows for the processing of virtually all types of organic waste (e.g. industrial or municipal) into syngas. The potential of syngas fermentation is evident by the advent of large-scale projects. Lanza Tech is working with steel manufactures [85] and coal producers [86] in China to make liquid fuels. BioMCN is converting glycerine to syngas which is fermented into bio-methanol and has constructed a 200000 ton/year pilot scale production unit [87]. Coskata [88] is commercializing the production of 
fuels and chemicals using a wide variety of biomass sources through syngas fermentation. They have built a demonstration-scale production facility as part of a feasibility study. Lastly, SYNPOL [89], a large research project funded by the $\mathrm{EU}$, is focused on the production of biopolymers via syngas fermentation. In order to fully utilize cheap carbon sources, however, construction of novel and optimized syngas fermenting strains for the production of biochemicals and biofuels is needed. Recent advances in our knowledge of energy conservation in acetogens and the development of new molecular biology tools provide a foundation for strain design strategies.

Recently developed genetic tools can be leveraged to achieve desirable phenotypic traits. Production of compounds of interest must be maximized under the conditions optimal for syngas fermentation. Further improvements will likely involve media optimization and evolution of strains for growth in minimal media. The formation of enhanced biofilm formers for some types of fermentations is highly desirable. Tolerance toward inhibitory substrate and product concentrations as well as other complex phenotypes may be achieved through ALE approaches. Lastly, genome-scale models for acetogens provide a valuable tool to account for the intricacies of acetogen metabolism when designing optimal production strains. With many of these enabling technologies now available, a significant growth in the research and metabolic engineering of acetogens can be expected to better utilize syngas for the production of both biofuels and commodity chemicals.

\section{Acknowledgements}

AAZ, ATN, and KZ acknowledge support from The Novo Nordisk Foundation. HL is supported through the National Science Foundation Graduate Research Fellowship under grant DGE1144086.

\section{References and recommended reading}

Papers of particular interest, published within the period of review, have been highlighted as:

- of special interest

• of outstanding interest

1. Directive 2009/28/EC of the European Parliament and of the Council of 23 April 2009 on the promotion of the use of energy from renewable sources and amending and subsequently repealing Directives 2001/77/EC and 2003/30/EC; 2009.

2. Energy Independence and Security Act of 2007. In Public Law 110-140; 2007.

3. Sims REH, Mabee W, Saddler JN, Taylor M: An overview of second generation biofuel technologies. Bioresour Technol 2010, 101:1570-1580.

4. Havlík P, Schneider UA, Schmid E, Böttcher H, Fritz S, Skalský R, Aoki K, Cara SD, Kindermann G, Kraxner F et al.: Global land-use implications of first and second generation biofuel targets. Energy Policy 2011, 39:5690-5702.

5. Hamelinck CN, Hooijdonk Gv Faaij APC: Ethanol from lignocellulosic biomass: techno-economic performance in short-, middle- and long-term. Biomass Bioenergy 2005, 28:384-410.
6. Betts WB, Dart RK, Ball AS, Pedlar SL: Biosynthesis and structure of lignocellulose. In Biodegradation. Edited by Betts WB. London: Springer; 1991:139-155.

7. Wang X, Padgett JM, De la Cruz FB, Barlaz MA: Wood biodegradation in laboratory-scale landfills. Environ Sci Technol 2011, 45:6864-6871.

8. Bugg TDH, Ahmad M, Hardiman EM, Singh R: The emerging role for bacteria in lignin degradation and bio-product formation. Curr Opin Biotechnol 2011, 22:394-400.

9. Richardson $\mathrm{Y}$, Blin J, Julbe A: A short overview on purification and conditioning of syngas produced by biomass gasification: catalytic strategies, process intensification and new concepts. Prog Energy Combust Sci 2012, 38:765-781.

10. Henstra AM, Sipma J, Rinzema A, Stams AJ: Microbiology of synthesis gas fermentation for biofuel production. Curr Opin Biotechnol 2007, 18:200-206.

11. Schiel-Bengelsdorf $B$, Dürre $P$ : Pathway engineering and synthetic biology using acetogens. FEBS Lett 2012, 586:21912198.

12. Munasinghe PC, Khanal SK: Syngas fermentation to biofuel: evaluation of carbon monoxide mass transfer coefficient (kLa) in different reactor configurations. Biotechnol Prog 2010, 26:1616-1621.

13. Drake HL, Gossner AS, Daniel SL: Old acetogens, new light. Ann N Y Acad Sci 2008, 1125:100-128.

14. Mohammadi M, Najafpour GD, Younesi H, Lahijani P, Uzir MH, Mohamed AR: Bioconversion of synthesis gas to second generation biofuels: a review. Renew Sust Energ Rev 2011, 15:4255-4273.

15. Munasinghe PC, Khanal SK: Biomass-derived syngas fermentation into biofuels: opportunities and challenges. Bioresour Technol 2010, 101:5013-5022.

16. Martin WF: Hydrogen, metals, bifurcating electrons, and proton gradients: the early evolution of biological energy conservation. FEBS Lett 2012, 586:485-493.

17. Buckel W, Thauer RK: Energy conservation via electron

-. bifurcating ferredoxin reduction and proton/ $\mathrm{Na}(+)$ translocating ferredoxin oxidation. Biochim Biophys Acta 2013, 1827:94-113.

A detailed review of the structure and functions of flavin-containing multienzyme complexes in anaerobes catalyzing the reduction of the low potential ferredoxin by electron donors with higher potentials.

18. Ragsdale SW: Enzymology of the Wood-Ljungdahl pathway of acetogenesis. Ann N Y Acad Sci 2008, 1125:129-136.

19. Ragsdale SW, Pierce E: Acetogenesis and the Wood-Ljungdahl pathway of $\mathrm{CO}_{2}$ fixation. Biochim Biophys Acta 2008, 1784:18731898.

20. Diekert G, Wohlfarth G: Metabolism of homocetogens. Antonie van Leeuwenhoek 1994, 66:209-221.

21. Köpke M, Held C, Hujer S, Liesegang H, Wiezer A, Wollherr A, Ehrenreich A, Liebl W, Gottschalk G, Dürre P: Clostridium ljungdahlii represents a microbial production platform based on syngas. Proc Natl Acad Sci U S A 2010, 107:13087-13092.

22. Nagarajan $\mathrm{H}$, Sahin M, Nogales J, Latif H, Lovley D, Ebrahim A, Zengler K: Characterizing acetogenic metabolism using a genome-scale metabolic reconstruction of Clostridium ljungdahlii. Microb Cell Fact 2013, 12:118.

23. van der Drift A, van Doorn J, Vermeulen JW: Ten residual biomass fuels for circulating fluidized-bed gasification. Biomass Bioenergy 2001, 20:45-56.

24. Das A, Ljungdahl LG: Electron-transport system in acetogens. In Biochemistry and physiology of anaerobic bacteria. Edited by Ljungdahl LG, Adams MW, Barton LL, Ferry JG, Johnson MK. New York: Springer; 2003:191-204.

25. Müller V: Energy conservation in acetogenic bacteria. Appl Environ Microbiol 2003, 69:6345-6353. 
26. Pierce E, Xie G, Barabote RD, Saunders E, Han CS, Detter JC Richardson P, Brettin TS, Das A, Ljungdahl LG et al.: The complete genome sequence of Moorella thermoacetica (f. Clostridium thermoaceticum). Environ Microbiol 2008, 10:25502573.

27. Biegel E, Schmidt S, Gonzalez JM, Müller V: Biochemistry, and physiological function of the Rnf complex, a novel ion-motive electron transport complex in prokaryotes. Cell Mol Life Sci Evolut 2011, 68:613-634.

28. Imkamp F, Biegel E, Jayamani E, Buckel W, Müller V: Dissection of the caffeate respiratory chain in the acetogen Acetobacterium woodii: identification of an Rnf-type NADH dehydrogenase as a potential coupling site. J Bacteriol 2007 , 189:8145-8153.

29. Biegel E, Müller V: Bacterial $\mathrm{Na}^{+}$-translocating ferredoxin:NAD oxidoreductase. Proc Natl Acad Sci U S A 2010, 107:1813818142.

30. Biegel E, Schmidt S, Müller V: Genetic, immunological and biochemical evidence for a Rnf complex in the acetogen Acetobacterium woodii. Environ Microbiol 2009, 11:1438-1443.

31. Poehlein A, Schmidt S, Kaster AK, Goenrich M, Vollmers J, Thurmer A, Bertsch J, Schuchmann K, Voigt B, Hecker M et al.: An ancient pathway combining carbon dioxide fixation with the generation and utilization of a sodium ion gradient for ATP synthesis. PLOS ONE 2012, 7:e33439.

32. Tremblay PL, Zhang T, Dar SA, Leang C, Lovley DR: The Rnf

- complex of Clostridium ljungdahlii is a proton-translocating ferredoxin:NAD ${ }^{+}$oxidoreductase essential for autotrophic growth. mBio 2012, 4:e00406-e00412.

This study utilized genetic manipulation tools to knock-out Rnf genes in $C$. ljungdahlii to verify that the complex is essential for autotrophic growth.

33. Schuchmann K, Müller V: A bacterial electron-bifurcating hydrogenase. J Biol Chem 2012, 287:31165-31171.

34. Huang $\mathrm{H}$, Wang S, Moll J, Thauer RK: Electron bifurcation

- involved in the energy metabolism of the acetogenic bacterium Moorella thermoacetica growing on glucose or $\mathrm{H}_{2}$ plus $\mathbf{C O}_{2}$. J Bacteriol 2012, 194:3689-3699.

This study identified a flavin-based electron bifurcation complex in $M$. thermoacetica which utilize electron transport phosphorylation for energy generation.

35. Wang S, Huang H, Kahnt J, Thauer RK: A reversible electronbifurcating ferredoxin- and NAD-dependent [FeFe]hydrogenase (HydABC) in Moorella thermoacetica. J Bacteriol 2013, 195:1267-1275.

36. Wang S, Huang H, Kahnt J, Mueller AP, Köpke M, Thauer RK: NADP-specific electron-bifurcating [FeFe]-hydrogenase in a functional complex with formate dehydrogenase in Clostridium autoethanogenum grown on CO. J Bacteriol 2013, 195:4373-4386.

37. Wang $\mathrm{S}$, Huang $\mathrm{H}$, Moll J, Thauer RK: NADP ${ }^{+}$reduction with reduced ferredoxin and $\mathrm{NADP}^{+}$reduction with $\mathrm{NADH}$ are coupled via an electron-bifurcating enzyme complex in Clostridium kluyveri. J Bacteriol 2010, 192:5115-5123.

38. Bertsch J, Parthasarathy A, Buckel W, Müller V: An electronbifurcating caffeyl-CoA reductase. J Biol Chem 2013, 288:11304-11311.

39. Leang C, Ueki T, Nevin KP, Lovley DR: A genetic system for

- Clostridium ljungdahlii: a chassis for autotrophic production of biocommodities and a model homoacetogen. Appl Environ Microbiol 2012, 79:1102-1109.

The authors improved transformation efficiency and demonstrated chromosomal gene deletion for Clostridium ljungdahlii.

40. Kita A, Iwasaki Y, Yano S, Nakashimada Y, Hoshino T, Murakami K: Isolation of thermophilic acetogens and transformation of them with the pyrF and kan genes. Biosci Biotechnol Biochem 2013, 77:301-306.

41. Kita A, Iwasaki Y, Sakai S, Okuto S, Takaoka K, Suzuki T, Yano S,

- Sawayama S, Tajima T, Kato J et al.: Development of genetic transformation and heterologous expression system in carboxydotrophic thermophilic acetogen Moorella thermoacetica. J Biosci Bioeng 2013, 115:347-352.
First report on transformation of a targeted chromosomal gene deletion in the model thermophilic acetogen Moorella thermoacetica.

42. Iwasaki Y, Kita A, Sakai S, Takaoka K, Yano S, Tajima T, Kato J, Nishio N, Murakami K, Nakashimada Y: Engineering of a functional thermostable kanamycin resistance marker for use in Moorella thermoacetica ATCC39073. FEMS Microbiol Lett 2013, 343:8-12.

43. Tripathi SA, Olson DG, Argyros DA, Miller BB, Barrett TF Murphy DM, McCool JD, Warner AK, Rajgarhia VB, Lynd LR et al.: Development of pyrF-based genetic system for targeted gene deletion in Clostridium thermocellum and creation of a pta mutant. Appl Environ Microbiol 2010, 76:6591-6599.

44. Heap JT, Kuehne SA, Ehsaan M, Cartman ST, Cooksley CM, Scott JC, Minton NP: The ClosTron mutagenesis in Clostridium refined and streamlined. J Microbiol Methods 2010, 80:49-55.

45. Heap JT, Pennington OJ, Cartman ST, Carter GP, Minton NP: The ClosTron: a universal gene knock-out system for the genus Clostridium. J Microbiol Methods 2007, 70:452-464.

46. Kuehne SA, Heap JT, Cooksley CM, Cartman ST, Minton NP:

•- ClosTron-mediated engineering of Clostridium. Methods $\mathrm{Mol}$ Biol 2011, 765:389-407.

The authors provide a detailed protocol for the use of bacterial group II intron-mediated engineering in Clostridium (ClosTron technology).

47. Bi C, Jones SW, Hess DR, Tracy BP, Papoutsakis ET: SpollE is necessary for asymmetric division, sporulation, and expression of $\sigma^{\mathrm{F}}, \sigma^{\mathrm{E}}$, and $\sigma^{\mathrm{G}}$ but does not control solvent production in Clostridium acetobutylicum ATCC 824. J Bacteriol 2011, 193:5130-5137.

48. Jones SW, Tracy BP, Gaida SM, Papoutsakis ET: Inactivation of $\sigma^{\mathrm{F}}$ in Clostridium acetobutylicum ATCC 824 blocks sporulation prior to asymmetric division and abolishes $\sigma^{\mathrm{E}}$ and $\sigma^{G}$ protein expression but does not block solvent formation. $J$ Bacteriol 2011, 193:2429-2440.

49. Tracy BP, Papoutsakis ET. Methods and compositions for genetically engineering Clostridia species. US patent 2012/ 0301964 A1. November 2012.

50. Harris LM, Welker NE, Papoutsakis ET: Northern, morphological, and fermentation analysis of spoOA inactivation and overexpression in Clostridium acetobutylicum ATCC 824. J Bacteriol 2002, 184:3586-3597.

51. Al-Hinai MA, Fast AG, Papoutsakis ET: Novel system for efficient isolation of Clostridium double-crossover allelic exchange mutants enabling markerless chromosomal gene deletions and DNA integration. Appl Environ Microbiol 2012, 78:81128121.

52. Heap JT, Ehsaan M, Cooksley CM, Ng YK, Cartman ST, Winzer K

- Minton NP: Integration of DNA into bacterial chromosomes from plasmids without a counter-selection marker. Nucleic Acids Res 2012, 40:e59.

Describes novel strategies for the selection of double-crossover clones at certain genomic loci without using a plasmid-borne counter-selection marker, which are applicable to Clostridium species.

53. Tummala SB, Welker NE, Papoutsakis ET: Design of antisense RNA constructs for downregulation of the acetone formation pathway of Clostridium acetobutylicum. J Bacteriol 2003, 185:1923-1934.

54. Cartman ST, Minton NP: A mariner-based transposon system for in vivo random mutagenesis of Clostridium difficile. Appl Environ Microbiol 2010, 76:1103-1109.

55. Liu H, Bouillaut L, Sonenshein AL, Melville SB: Use of a marinerbased transposon mutagenesis system to isolate Clostridium perfringens mutants deficient in gliding motility. $J$ Bacteriol 2013, 195:629-636.

56. Blouzard JC, Valette O, Tardif C, de Philip P: Random mutagenesis of Clostridium cellulolyticum by using a Tn1545 derivative. Appl Environ Microbiol 2010, 76:4546-4549.

57. Daniell J, Köpke M, Simpson S: Commercial biomass syngas fermentation. Energies 2012, 5:5372-5417. 
58. Perez JM, Richter H, Loftus SE, Angenent LT: Biocatalytic reduction of short-chain carboxylic acids into their corresponding alcohols with syngas fermentation. Biotechnol Bioeng 2013, 110:1066-1077.

59. Merchuk JC, Siegel MH: Air-lift reactors in chemical and biological technology. J Chem Technol Biotechnol 1988, 41:105-120.

60. Nerenberg R, Rittmann BE: Hydrogen-based, hollow-fiber membrane biofilm reactor for reduction of perchlorate and other oxidized contaminants. Water Sci Technol 2004 49:223-230.

61. Leang C, Malvankar NS, Franks AE, Nevin KP, Lovley DR: Engineering Geobacter sulfurreducens to produce a highly cohesive conductive matrix with enhanced capacity for current production. Energy Environ Sci 2013, 6:1901-1908.

62. Đapa T, Leuzzi R, Ng YK, Baban ST, Adamo R, Kuehne SA, Scarselli M, Minton NP, Serruto D, Unnikrishnan M: Multiple factors modulate biofilm formation by the anaerobic pathogen Clostridium difficile. J Bacteriol 2013, 195:545-555.

63. Dawson LF, Valiente E, Faulds-Pain A, Donahue EH, Wren BW:

- Characterisation of Clostridium difficile biofilm formation, a role for Spo0A. PLoS ONE 2012, 7:e50527.

Demonstrated the involvement of the sporulation regulator, SpoOA, in biofilm formation in the autotrophic bacterium Clostridium difficile.

64. Tracy BP, Jones SW, Fast AG, Indurthi DC, Papoutsakis ET: Clostridia: the importance of their exceptional substrate and metabolite diversity for biofuel and biorefinery applications. Curr Opin Biotechnol 2012, 23:364-381.

65. Deakin LJ, Clare S, Fagan RP, Dawson LF, Pickard DJ, West MR, Wren BW, Fairweather NF, Dougan G, Lawley TD: The Clostridium difficile spoOA gene is a persistence and transmission factor. Infect Immun 2012, 80:2704-2711.

66. Sillers R, Chow A, Tracy B, Papoutsakis ET: Metabolic engineering of the non-sporulating, non-solventogenic Clostridium acetobutylicum strain M5 to produce butanol without acetone demonstrate the robustness of the acid-formation pathways and the importance of the electron balance. Metab Eng 2008, 10:321-332.

67. Hamon MA, Lazazzera BA: The sporulation transcription factor Spo0A is required for biofilm development in Bacillus subtilis Mol Microbiol 2001, 42:1199-1209.

68. Blanchard J, Fabel J, Leschine S, Petit E. Methods and compositions for regulating sporulation. US patent 20100105114 A1. April 2010.

69. Winkler J, Reyes LH, Kao KC: Adaptive laboratory evolution for strain engineering. Methods Mol Biol 2013, 985:211-222.

70. Conrad TM, Lewis NE, Palsson BO: Microbial laboratory evolution in the era of genome-scale science. Mol Syst Biol 2011, 7:509.

71. Portnoy VA, Bezdan D, Zengler K: Adaptive laboratory evolution - harnessing the power of biology for metabolic engineering. Curr Opin Biotechnol 2011, 22:590-594.

72. Shen GJ, Shieh JS, Grethlein AJ, Jain MK, Zeikus JG: Biochemical basis for carbon monoxide tolerance and butanol production by Butyribacterium methylotrophicum. Appl Microbiol Biotechnol 1999, 51:827-832.
73. Goodarzi H, Bennett BD, Amini S, Reaves ML, Hottes AK, Rabinowitz JD, Tavazoie S: Regulatory and metabolic rewiring during laboratory evolution of ethanol tolerance in E. coli. Mol Syst Biol 2010, 6:378.

74. Horinouchi T, Tamaoka K, Furusawa C, Ono N, Suzuki S, Hirasawa T, Yomo T, Shimizu H: Transcriptome analysis of parallel-evolved Escherichia coli strains under ethanol stress. BMC Genomics 2010, 11:579.

75. Berzin V, Kiriukhin M, Tyurin M: Selective production of acetone during continuous synthesis gas fermentation by engineered biocatalyst Clostridium sp. MAceT113. Lett Appl Microbiol 2012, 55:149-154.

76. Berzin V, Kiriukhin M, Tyurin M: Elimination of acetate production to improve ethanol yield during continuous synthesis gas fermentation by engineered biocatalyst Clostridium sp. MTEtOH550. App/ Biochem Biotechnol 2012, 167:338-347.

77. Berzin V, Kiriukhin M, Tyurin M: Cre-lox66/lox71-based elimination of phosphotransacetylase or acetaldehyde dehydrogenase shifted carbon flux in acetogen rendering selective overproduction of ethanol or acetate. Appl Biochem Biotechnol 2012, 168:1384-1393.

78. Berzin V, Tyurin M, Kiriukhin M: Selective $\mathbf{n}$-butanol production by Clostridium sp. MTButOH1365 during continuous synthesis gas fermentation due to expression of synthetic thiolase, 3hydroxy butyryl-CoA dehydrogenase, crotonase, butyryl-CoA dehydrogenase, butyraldehyde dehydrogenase, and NADdependent butanol dehydrogenase. Appl Biochem Biotechnol 2013, 169:950-959.

79. Tyurin M, Kiriukhin M: Selective methanol or formate production during continuous $\mathrm{CO}$ fermentation by the acetogen biocatalysts engineered via integration of synthetic pathways using Tn7-tool. World J Microbiol Biotechnol 2013, 29:1611 1623.

80. Feist AM, Palsson BO: The growing scope of applications of genome-scale metabolic reconstructions using Escherichia coli. Nat Biotechnol 2008, 26:659-667.

81. Lee JW, Na D, Park JM, Lee J, Choi S, Lee SY: Systems metabolic engineering of microorganisms for natural and nonnatural chemicals. Nat Chem Biol 2012, 8:536-546.

82. Park JH, Kim TY, Lee KH, Lee SY: Fed-batch culture of Escherichia coli for L-valine production based on in silico flux response analysis. Biotechnol Bioeng 2011, 108:934-946.

83. Gao J, Atiyeh HK, Phillips JR, Wilkins MR, Huhnke RL: Development of low cost medium for ethanol production from syngas by Clostridium ragsdalei. Bioresour Technol 2013, 147:508-515.

84. Richter H, Martin M, Angenent L: A two-stage continuous fermentation system for conversion of syngas into ethanol. Energies 2013, 6:3987-4000.

85. LanzaTech: Chinese Steel Miller Commercializing LanzaTech's Clean Energy Technology. 2011.

86. LanzaTech: LanzaTech joins China's Yankuang Group on coal to fuel project. 2011.

87. BioMCN: http://www.biomcn.eu/. 2013.

88. Coskata: www.coskata.com. 2013.

89. SYNPOL: http://www.synpol.org/. 2013. 